\title{
The Surprise Examination or Unexpected Hanging Paradox
}

\author{
Timothy Y. Chow
}

[As published in Amer. Math. Monthly 105 (1998), 41-51; ArXived with permission.]

\begin{abstract}
Many mathematicians have a dismissive attitude towards paradoxes. This is unfortunate, because many paradoxes are rich in content, having connections with serious mathematical ideas as well as having pedagogical value in teaching elementary logical reasoning. An excellent example is the so-called "surprise examination paradox" (described below), which is an argument that seems at first to be too silly to deserve much attention. However, it has inspired an amazing variety of philosophical and mathematical investigations that have in turn uncovered links to Gödel's incompleteness theorems, game theory, and several other logical paradoxes (e.g., the liar paradox and the sorites paradox). Unfortunately, most mathematicians are unaware of this because most of the literature has been published in philosophy journals.

In this article, I describe some of this work, emphasizing the ideas that are particularly interesting mathematically. I also try to dispel some of the confusion that surrounds the paradox and plagues even the published literature. However, I do not try to correct every error or explain every idea that has ever appeared in print. Readers who want more comprehensive surveys should see [30, chapters 7 and 8], [20], and [16].
\end{abstract}

At times I assume some knowledge of mathematical logic (such as may be found in Enderton [10]), but the reader who lacks this background may safely skim these sections.

\section{The paradox and the meta-paradox}

Let us begin by recalling the paradox. It has many variants, the earliest probably being Lennart Ekbom's surprise drill, and the best known to mathematicians (thanks to Quine and Gardner) being an unexpected hanging. We shall give the surprise examination version.

A teacher announces in class that an examination will be held on some day during the following week, and moreover that the examination will be a surprise. The students argue that a surprise exam cannot occur. For suppose the exam were on the last day of the week. Then on the previous night, the students would be able to predict that the exam would occur on the following day, and the exam would not be a surprise. So it is impossible for a surprise exam to occur on the last day. But then a surprise exam cannot occur on the penultimate day, either, for in that case the students, knowing that the last day is an impossible day for a surprise exam, would be able to predict on the night before the exam that the exam would occur on the following day. Similarly, the students argue that a surprise exam cannot occur on any other day of the week either. Confident in this conclusion, they are of course totally surprised when the exam occurs 
(on Wednesday, say). The announcement is vindicated after all. Where did the students' reasoning go wrong?

The natural reaction to a paradox like this is to try to resolve it. Indeed, if you have not seen this paradox before, I encourage you to try to resolve it now before reading on. However, I do not want to discuss the resolution of the paradox right away. Instead, for reasons that should become apparent, I discuss what I call the "meta-paradox" first.

The meta-paradox consists of two seemingly incompatible facts. The first is that the surprise exam paradox seems easy to resolve. Those seeing it for the first time typically have the instinctive reaction that the flaw in the students' reasoning is obvious. Furthermore, most readers who have tried to think it through have had little difficulty resolving it to their own satisfaction.

The second (astonishing) fact is that to date nearly a hundred papers on the paradox have been published, and still no consensus on its correct resolution has been reached. The paradox has even been called a "significant problem" for philosophy [30, chapter 7, section VII]. How can this be? Can such a ridiculous argument really be a major unsolved mystery? If not, why does paper after paper begin by brusquely dismissing all previous work and claiming that it alone presents the long-awaited simple solution that lays the paradox to rest once and for all?

Some other paradoxes suffer from a similar meta-paradox, but the problem is especially acute in the case of the surprise examination paradox. For most other trivialsounding paradoxes there is broad consensus on the proper resolution, whereas for the surprise exam paradox there is not even agreement on its proper formulation. Since one's view of the meta-paradox influences the way one views the paradox itself, I must try to clear up the former before discussing the latter.

In my view, most of the confusion has been caused by authors who have plunged into the process of "resolving" the paradox without first having a clear idea of what it means to "resolve" a paradox. The goal is poorly understood, so controversy over whether the goal has been attained is inevitable. Let me now suggest a way of thinking about the process of "resolving a paradox" that I believe dispels the meta-paradox.

In general, there are two steps involved in resolving a paradox. First, one establishes precisely what the paradoxical argument is. Any unclear terms are defined carefully and all assumptions and logical steps are stated clearly and explicitly, possibly in a formal language of some kind. Second, one finds the fault in the argument. Sometimes, simply performing step one reveals the flaw, e.g., when the paradox hinges on confusing two different meanings of the same word, so that pointing out the ambiguity suffices to dispel the confusion. In other cases, however, something more needs to be done; one must locate the bad assumptions, the bad reasoning, or (in desperate circumstances) the flaw in the structure of logic itself. 
These two steps seem straightforward, but there are a few subtleties. For example, if, in the second step, the flaw is caused by bad assumptions, it may be hard to isolate a unique culprit. Sometimes what we discover is a set of mutually incompatible assumptions such that rejecting any one of them suffices to eliminate the contradiction. When this occurs, however, notice that while it may be an interesting question to decide which assumption to reject, such a decision is not usually needed to resolve the paradox. It is usually enough to exhibit the incompatible assumptions and state that their joint inconsistency is the source of the paradox.

The first step of resolving a paradox can also be subtle. As many investigators of the surprise exam paradox have noted, formal versions of a paradox sometimes miss the essence of the original informal version. Such a mistranslation evades the paradox instead of resolving it. Certainly, this is a real danger, and numerous authors have fallen into this trap. However, there is a simple but important point here that is often overlooked: the question of whether or not a particular formalization of a paradox "captures its essence" is to some extent a matter of opinion. Given two formalizations of the paradox, one person may think that the first captures the essence better but another may prefer the second. One cannot say who is objectively right, since there is always some vagueness in the original informal account. To be sure, one can sometimes argue that a particular formalization is inadequate by proposing a variation of the paradox that seems to retain its essence but for which the particular formalization fails. Even here, though, there is some room for differences of opinion, because one can sometimes argue that the variant paradox does not in fact retain the essence but is actually a different paradox that requires a different solution.

Thus, sometimes there exist multiple formalizations of a paradox that all capture its essence reasonably well. In such cases I believe it is misguided to speak of the resolution of the paradox. This point has also been made by Kirkham [16].

With these ideas in mind we can easily explain the meta-paradox. A careful look at the literature confirms our suspicion that the paradox is not hard to resolve, because most authors have succeeded in finding resolutions. Most of the controversies have been false controversies. For example, there has been much debate between what I call the "epistemological school" (which formalizes the paradox using concepts such as knowledge, belief and memory) and the "logical school" (which avoids such concepts) over who has the "right" formalization. But both approaches are reasonable and neither is guilty of evasion.

Also, within the epistemological school there has been much debate over which axiom of a certain set of mutually inconsistent axioms about knowledge should be rejected. The question is an interesting one from the point of view of philosophically analyzing the concept of knowledge, but if we agree that identifying the "right" axiom to reject is not essential to resolving the paradox then this debate need not trouble us. 
Having dealt with the meta-paradox, we now turn to the paradox itself and explore several different approaches.

\section{The logical school}

We mathematicians have a firm belief that logic and mathematics are consistent. When we are confronted with a paradox, therefore, our tendency is to assume, even before analyzing the paradox, that either the paradox cannot be translated into a purely logical or mathematical argument, or that if it can be so translated, the faulty step or assumption will become immediately apparent. So a natural reaction to the surprise examination paradox (at least for a mathematician) is to take the students' argument and try to convert it into a rigorous proof in order to find the flaw. Let us now do this and see what happens.

Every proof begins with axioms. The students' argument seems to deduce a contradiction from the teacher's announcement, so it seems that the axioms in this case ought to be some formalization of the announcement. Now, part of the announcement-the claim that an examination will take place some time during the following week-is not difficult to formalize, but the part that says that the examination will be a surprise is not as clear. What is meant by "surprise"?

Whatever "surprise" means, it must at least mean that the students will not be able to deduce logically the date of the examination ahead of time, for if the students could prove that the date of the examination were such-and-such before the date arrived, they would surely not be at all surprised by the exam. So a first step towards formalizing the teacher's announcement might be, "There will be an examination next week and its date will not be deducible in advance."

This is not sufficient, however, because every proof begins with axioms. To say that the date of the examination will not be deducible in advance is a vague statement until the axioms from which the date cannot be deduced are specified precisely. Now, it is not completely clear which axioms are in question here; the informal word "surprise" is too vague to give us many clues. However, if our formalization is to be at all true to the original paradox, it should at least allow us to formalize the students' argument to some degree. Formalizing the teacher's announcement as

(a) There will be an examination next week and its date will not be deducible in advance from an empty set of assumptions

is certainly not satisfactory because it does not allow the students' argument even to begin. This would evade the paradox and not resolve it.

A better attempt at formalization might be something like

(b) There will be an examination next week and its date will not be deducible in advance from the assumption that the examination will occur some time during the week. 
This formalization allows at least the first step of the students' argument to be carried out: given this announcement, the students can deduce that the examination will not occur on the last day of the week. However, if we try to reproduce the next step of the students' argument-the step that eliminates the penultimate day of the week-we find ourselves stuck. In order to eliminate the penultimate day, the students need to argue that their ability to deduce, from statement (b), that the examination will not occur on the last day implies that a last-day examination will not be surprising. But since we have restricted "surprising" to mean "not deducible from the assumption that the examination will occur sometime during the week" instead of "not deducible from statement (b)," the students' argument is blocked. To continue the argument we need to be able to use the nondeducibility from the announcement as an assumption, i.e., we must embed the nondeducibility from the announcement into the announcement itself.

It now becomes clear that to carry out the students' argument, one needs a formalization that is something like

(c) There will be an examination next week and its date will not be deducible in advance using this announcement as an axiom.

In other words, the announcement must be formulated as a self-referential statement!

There is a temptation to end the analysis here with a comment that the self-referential nature of statement (c) is the source of the paradox. After all, if a self-referential definition like this were to be presented in a mathematical paper, we would surely reject it instantly as illegal. Indeed, Shaw concludes his paper [25] with just such a comment.

However, we need to be careful. For it is possible in mathematics to formalize certain kinds of self-referential statements. Indeed, this was one of the crucial ideas in Gödel's proof of his incompleteness theorems, and it is now a standard technique in mathematical logic. It is natural to ask if this technique can be used to obtain a completely formal version of statement (c). The answer is yes; we give the construction (due to Fitch [11]; [4] and [32] have similar constructions) in some detail since it is rather interesting.

Let us reduce the number of days to two for simplicity (we consider one-day weeks shortly), and let $Q_{1}$ and $Q_{2}$ be statements representing the occurrence of the exam on days one and two, respectively. Then what we are seeking is a statement $S$ such that

$$
S \equiv\left(Q_{1} \&\left(\left[S \Rightarrow Q_{1}\right] \text { is unprovable }\right)\right) \text { or else }\left(Q_{2} \&\left(\left[S \& \sim Q_{1} \Rightarrow Q_{2}\right] \text { is unprovable }\right)\right) .
$$

Given a first-order language that contains enough elementary arithmetic to handle primitive recursive functions, together with some Gödel numbering of the formulas, it is straightforward to formalize most aspects of this statement. There are primitive recursive functions "Neg," "Conj," and "Imp" encoding negation, conjunction, and implication (i.e., if $q$ is the Gödel number of $Q$ then Neg $q$ is the Gödel number of the negation of $Q$, and so on), and a primitive recursive relation $R$ that relates $i$ to $j$ if and only if $i$ is the Gödel 
number of a proof of the sentence whose Gödel number is $j$. The only tricky part is the self-reference, and this is achieved using the usual (primitive recursive) "diagonalization" operator $D: D(m, n)$ is the Gödel number of the sentence obtained by replacing the free variable in the formula having Gödel number $m$ by the name of the number $n$.

Now let $q_{1}$ and $q_{2}$ be the Gödel numbers of $Q_{1}$ and $Q_{2}$ respectively, let $\not \equiv$ denote exclusive or, and let $P[x]$ abbreviate $\exists y: y R x$. $P$ stands for provable. Then we can formulate the following formula with the free variable $x$ :

$$
\left(Q_{1} \& \sim P\left[D(x, x) \operatorname{Imp} q_{1}\right]\right) \not \equiv\left(Q_{2} \& \sim P\left[\left(D(x, x) \text { Conj Neg } q_{1}\right) \operatorname{Imp} q_{2}\right]\right) .
$$

Let $h$ be the Gödel number of this formula, and let $S$ be the sentence obtained by substituting $h$ for $x$, i.e.,

$$
\left(Q_{1} \& \sim P\left[D(h, h) \operatorname{Imp} q_{1}\right]\right) \not \equiv\left(Q_{2} \& \sim P\left[\left(D(h, h) \text { Conj Neg } q_{1}\right) \operatorname{Imp} q_{2}\right]\right) .
$$

Then, by definition of $D, D(h, h)$ is the Gödel number of $S$. The clincher is that $D(h, h)$ also appears on the right-hand side of $(\dagger)$ exactly where we want it to appear. Using "\#" to denote "the name of the Gödel number of" we can rewrite $S$ as

$$
\left(Q_{1} \& \sim P\left[\#\left(S \Rightarrow Q_{1}\right)\right]\right) \not \equiv\left(Q_{2} \& \sim P\left[\#\left(\left(S \& \sim Q_{1}\right) \Rightarrow Q_{2}\right)\right]\right) .
$$

This completes the formalization of statement (c). We can now imitate the students' argument to show that $S$ is logically false, i.e., that $\sim S$ is a tautology. Using the definition of $S$, we can prove

$$
\left(S \& \sim Q_{1}\right) \Rightarrow Q_{2} .
$$

Let $a$ be the Gödel number of (1). By the nature of the relation $R$, the provability of (1) implies $P(a)$. But observe that $\sim P(a)$ appears in the second disjunct in the definition of $S$. It follows that

$$
S \Rightarrow Q_{1}
$$

The rest of the argument is now clear: if $b$ is the Gödel number of (2), then the provability of (2) implies $P(b)$, but $\sim P(b)$ appears in the first disjunct of $S$. Therefore $\sim S$.

Thus, although self-reference is not illegitimate in all circumstances, it is illegitimate here because this particular self-referential statement is self-contradictory. Fitch's proof has a satisfying air of definitiveness, and seems to vindicate Shaw.

However, various authors have raised objections to this analysis. The most important is that the proof does not give any explanation for why the teacher's announcement appears to be vindicated after the fact. It appears to pin the blame on the teacher's announcement instead of on the students, and surely this cannot be correct. 
A related objection rests on the observation that if the teacher had not announced the exam to the class but had simply decided in secret to give a surprise exam, then no paradox would have occurred. Therefore the trouble cannot be attributed solely to the propositional content of the teacher's announcement; the act of announcing it to the students must play a crucial role. The purely logical analysis seems to ignore this.

These objections have convinced many to reject entirely the "purely logical" approach, and to propose a different, "epistemological" approach.

Before moving on to a discussion of the epistemological school, however, I want to point out that the objections can be met. For example, the first objection indicates a misunderstanding of the purely logical approach. The conclusion of the logical analysis is not that the teacher's announcement is self-contradictory and is the source of the paradox. Rather, the conclusion is that in order for the students to carry out their argument that the teacher's announcement cannot be fulfilled, they must interpret the teacher's announcement as saying something like (c). If the teacher intended (c) when making the announcement, then it would be contradictory, and would remain so after the examination. However, a more reasonable assumption is that the teacher's announcement, whatever it means, does not mean (c), and that therefore the students misinterpret the announcement when they make their argument. The announcement appears to be vindicated afterwards, but the statement that is actually vindicated is something like "the students will be psychologically surprised by the exam," and such a statement does not permit the students' argument to be carried out. Similar observations are made in [4] and [9].

As for the objection about the role of the act of making the announcement, observe that the same sequence of words can have different meanings depending on context, and that in the case of the teacher's announcement, the public utterance of the sentence changes its propositional content from "there will be a surprise exam" to something like "there will be a surprise exam in spite of the fact that I am now telling you that there will be a surprise exam." The logical analysis therefore does take into account the act of making the announcement, albeit implicitly, in its definition of the word "surprise." Ignoring the act of making the announcement would leave us stuck at (a).

\section{The epistemological school}

The purely logical approach is attractive to a mathematician both because it shows exactly what problems arise from trying to convert the paradoxical argument into a mathematical proof and because it has connections to nontrivial theorems of logic. However, it has one serious disadvantage: certain aspects of the paradox-the act of announcing the exam, the belief or disbelief that the students have in the announcement, their assumption that they will remember the announcement during the course of the week, and so on-are taken into account only implicitly and not explicitly. It is therefore natural to ask if we can formalize the paradox in a way that lays bare these "epistemic" aspects. 
Various epistemological formalizations have been proposed in the literature; we give just one here (taken from [29]) to illustrate the idea. As before, reduce the number of days to two for simplicity; let " 1 " denote "the exam occurs on the first day" and let " 2 " denote "the exam occurs on the second day." Let "Ka" denote "on the eve of the first day the students will know" and let "Kb" denote "on the eve of the second day the students will know." The announcement can then be written

$$
[1 \Rightarrow \sim \mathrm{Ka} 1] \&[2 \Rightarrow(\sim \mathrm{Kb} 2 \& \mathrm{~Kb} \sim 1)] \&[1 \vee 2]
$$

We now introduce certain assumptions about knowledge and add them to our list of rules of inference in our logic.

KD: If one knows $A \& B$, then one knows $A$ and one knows $B$. Similarly, if one knows that $A$ implies $B$ and one knows $A$, then one knows $B$.

KI: All logical truths are known.

KE: It is not possible to know something that is false.

We begin the argument with a lemma: $\mathrm{Kb}(\ddagger) \Rightarrow \sim 2$; remember that " $\Rightarrow$ " here encompasses our new rules of logic $\mathrm{KD}, \mathrm{KI}$, and $\mathrm{KE}$. Assume that $\mathrm{Kb}(\ddagger)$ is true. By $\mathrm{KD}$, it follows that $\mathrm{Kb}[1 \vee 2]$. Now assume towards a contradiction that 2 is true, i.e., the exam is held on the last day. From $\mathrm{Kb}(\ddagger)$ and $\mathrm{KE}$, ( $\ddagger)$ follows, and 2 together with second conjunct of $(\ddagger)$ implies $\sim \mathrm{Kb} 2 \& \mathrm{~Kb} \sim 1$; in particular, $\sim \mathrm{Kb} 2$. On the other hand, using $\mathrm{KD}$, we deduce from $\mathrm{Kb}[1 \vee 2]$ and $\mathrm{Kb} \sim 1$ that $\mathrm{Kb} 2$, a contradiction. Thus, $\mathrm{Kb}(\ddagger)$ implies $\sim 2$, and by $\mathrm{KI}$ we can infer $\mathrm{Ka}[\mathrm{Kb}(\ddagger) \Rightarrow \sim 2]$.

Now we can proceed with the crux of the argument: deducing a contradiction from the assumption $\mathrm{KaKb}(\ddagger)$. Assume $\mathrm{KaKb}(\ddagger)$. From $\mathrm{KD}$ and $\mathrm{Ka}[\mathrm{Kb}(\ddagger) \Rightarrow \sim 2]$ it follows that $\mathrm{Ka} \sim 2$. It is one of our logical truths (KE) that $\mathrm{Kb}(\ddagger) \Rightarrow(\ddagger)$, so from $\mathrm{KI}$ we conclude that $\mathrm{Ka}[\mathrm{Kb}(\ddagger) \Rightarrow(\ddagger)]$. By $\mathrm{KD}$ and our assumption that $\mathrm{KaKb}(\ddagger)$, this implies $\mathrm{Ka}(\ddagger)$ and in particular (by KD again) that $\mathrm{Ka}(1 \vee 2)$. Since we know that $\mathrm{Ka} \sim 2$, it follows from KD that $\mathrm{Ka} 1$. But since $\mathrm{Ka}(\ddagger)$ is true, $(\ddagger)$ is true (by KE), and in particular its first disjunct $1 \Rightarrow$ $\sim \mathrm{Ka} 1$ is true. Then from Ka 1 we deduce 1 (from KE) and hence $\sim \mathrm{Ka} 1$, a contradiction.

This shows that certain plausible assumptions about knowledge-KI, KD, and KE, together with the assumption that the students know that they will know the content of the announcement throughout the week-are inconsistent. Pointing out to the students that they are making these internally inconsistent assumptions about knowledge is enough to dissolve the paradox; we do not necessarily have to decide which assumption is the "wrong" one.

It is still interesting, however, to see if one of the assumptions appears to be a particularly promising candidate for rejection. Perhaps the most popular candidate has been the assumption that after hearing the announcement, the students "know" the content of the 
announcement. Those who maintain that we can never "know" things by authority or that we can never "know" things about the future (at least not with the same certainty that we can know many other things) naturally find this approach attractive. However, even those who are less skeptical have reason to reject the assumption, because the statement that the students are supposed to "know" is a statement that says something about the students" inability to "know" certain things. For comparison, consider the statement, "It is raining but John Doe does not know that it is raining." Clearly, John Doe cannot know the content of this statement even if the statement is true and it is uttered in his hearing by an extraordinarily reliable source. This curious phenomenon is known as a "Moore paradox" or a "blindspot," and the surprise exam paradox may be viewed as simply a more intricate version of this situation. The easiest way to see the connection is to reduce the length of the week to one day, so that the announcement becomes, "There will be an exam tomorrow but you do not know that." This approach is essentially the one offered in [3], [6], [18], [21], [22], [24], and [29].

Others have argued that the assumption $\mathrm{KaKb}(\ddagger)$ is plausible only if one invokes the "temporal retention principle" (the students know that they will not forget the announcement during the week) or "Hintikka's KK principle" (if one knows something then one knows that one knows it), and that one or both of these assumptions should be discarded. I do not discuss this in detail here since I feel it is of limited mathematical interest, but I mention a brilliant variation of the paradox concocted by Sorensen [28], which suggests that rejecting these assumptions may be missing the point.

Exactly one of five students, Art, Bob, Carl, Don, and Eric, is to be given an exam. The teacher lines them up alphabetically so that each student can see the backs of the students ahead of him in alphabetical order but not the students after him. The students are shown four silver stars and one gold star. Then one star is secretly put on the back of each student. The teacher announces that the gold star is on the back of the student who must take the exam, and that that student will be surprised in the sense that he will not know he has been designated until they break formation. The students argue that this is impossible; Eric cannot be designated because if he were he would see four silver stars and would know that he was designated. The rest of the argument proceeds in the familiar way. The significance of this variation is that in our preceding formalization we can let Ka mean "Art knows" and Kb mean "Bob knows" and then $\mathrm{KaKb}(\ddagger)$ appears to be immediately plausible without reference to time or the KK principle. Thus, the problem remains even if those principles are rejected; see [28] and [16] for more discussion.

A very interesting variant of the epistemological approach, that of Kaplan and Montague [15], is a kind of hybrid of the logical and epistemological schools. They prove a theorem called "the Paradox of the Knower" that is reminiscent of Tarski's theorem on the indefinability of the truth predicate. Suppose we we have a first-order language and we wish to introduce a knowledge predicate $K$. There are certain reasonable-sounding conditions that we might want to place on $K$ : 
(A) $K(\# Q) \Rightarrow Q$;

(B) (A) is known, i.e., $K(\# \mathrm{~A})$;

(C) if $Q$ can be proved from $P$ and $K(\# P)$, then $K(\# Q)$.

Unfortunately, these assumptions cannot be satisfied. Using a diagonalization argument, we can construct a sentence $S$ such that $S \equiv K(\#(\sim S))$, and then derive a contradiction by substituting this $S$ for $Q$ and $A$ for $P$ in (A), (B), and (C). Thus, no such knowledge predicate is possible.

One might think at first that $(\mathrm{C})$ is the dubious assumption since certainly nobody knows all the logical consequences of what he knows, but (C) can be weakened to the assumption that the logical conclusion of a particular explicitly given proof is known, so the theorem is quite a strong one. The Paradox of the Knower has inspired some sophisticated work in logic; see [1], [2], or [13].

\section{Game theory}

Some authors have made the fascinating suggestion that the surprise exam paradox may be related to the iterated prisoner's dilemma. The prisoner's dilemma is a two-player game in which each player has the choice of either defecting or cooperating and must make the choice without communicating with the other player and without prior knowledge of the other player's choice. If one player defects and the other player cooperates, then the defector enjoys a large payoff and the cooperator suffers a large loss. If both players defect then both payoffs are zero, and if both players cooperate then they both earn a moderate payoff. It is easy to show that each player has a dominant strategy (i.e., one that is better than any other strategy regardless of the opponent's strategy): to defect.

Intuitively, defection is the best choice because the prisoner's dilemma is a "one-shot" game; there is no incentive for players to build up a cooperative relationship since they are guaranteed never to meet again. This suggests considering the iterated prisoner's dilemma, in which there are $n$ rounds instead of just one (and the fact that there are exactly $n$ rounds is public knowledge). The payoffs in each round are as in the usual prisoner's dilemma, and the two players are still not allowed to communicate with each other, but at each round they do know and remember the results of all previous rounds. One might think that in this case, occasional cooperation would be superior to invariable defection-the idea being that a cooperative move in an early stage, even if the opponent defects, encourages future cooperation that counterbalances earlier losses.

Consider the following "surprise examination" argument that even in the n-round prisoner's dilemma, the optimal strategy is invariable defection. The last round of an iterated prisoner's dilemma is identical to the "one-shot" prisoner's dilemma, since there is no hope of future cooperation. Hence the optimal last-round strategy is to defect. But since defection in the last round is certain, there is no incentive in the penultimate round to 
cooperate, for doing so cannot possibly encourage future cooperation. Thus, the optimal strategy in the penultimate round is also defection. Proceeding by induction, we conclude that perfect players always defect.

The analogy between this argument and the standard surprise examination argument is quite striking at first. Indeed, Sorensen [30] has argued that the two are really the same, and has substantially revised his analysis of the surprise exam as a result. There is, however, an important disanalogy. In the iterated prisoner's dilemma, the conclusion about invariable defection is counterintuitive, but it does not lead to an explicit contradiction. It is not difficult to adapt our argument to give a fully rigorous mathematical proof that in the iterated prisoner's dilemma, a Nash equilibrium is possible only if both players defect in every round; see [12, p. 166]. (A Nash equilibrium is a situation in which if the strategies of all but one player are held fixed, that player cannot do better by changing strategies. One reason that the "surprise exam" argument we presented is not rigorous as it stands is that the word "optimal" is imprecise. A Nash equilibrium is a precise concept that captures some-though not all—of the connotations of the word "optimal.") Therefore, I believe that the iterated prisoner's dilemma is essentially distinct from the surprise examination paradox and is not just a variant; see [23].

Nevertheless, one might be able to exploit the parallel between the surprise examination and the iterated prisoner's dilemma to obtain some new ideas for game theory. After all, cooperation is observed in the real world, and this suggests that the usual mathematical model of the iterated prisoner's dilemma might ignore some crucial point. For some interesting ideas in this direction, see [17].

Finally, I want to mention an unpublished idea of Karl Narveson that illustrates how the surprise exam paradox can inspire new mathematics. A teacher gives a quiz every week, with probability $p_{1}$ on Monday, $p_{2}$ on Tuesday, and so on. The teacher's goal is to find a probability distribution that maximizes the absolute value of the expected surprise when the quiz is announced. Here "surprise" is based on Shannon entropy, so the surprise on Monday is $\log p_{1}$, the surprise on Tuesday is the $\log$ of the probability that the exam occurs on Tuesday given that it has not occurred on Monday, and so on until Friday, when the quiz becomes a certainty and its announcement no longer comes as a surprise.

Let $q_{n, m}$ be the probability that the exam occurs on the $n$ th-to-the-last day of an $m$-day week given that it has not occurred on any previous days, where $n$ ranges from zero to $m$ - 1. As one can easily show, the optimal value of $q_{n, m}$ is independent of $m$, so we drop the second subscript.

Now set $s_{0}=0$. Narveson has shown that $q_{n}$ is given by the mutual recursions

$$
\begin{aligned}
& q_{n}=\exp \left(s_{n-1}-1\right) \\
& s_{n}=s_{n-1}-q_{n}
\end{aligned}
$$


The $p^{\prime}$ s may then be recovered from the $q$ 's. For a five-day week, the probabilities for each of the five days are about $0.1620,0.1654,0.1713,0.1844$, and 0.3169 .

\section{Further reading}

The literature contains a wide variety of other approaches to the surprise examination paradox. Cargile [5] is the first paper in the literature to mention game theory. Clark [7] remarks that strictly mathematical analyses of the surprise exam are rare in the literature and he tries to fill this gap. Smullyan [27] weaves Gödel's theorem, brainteasers, the surprise exam, and other "epistemic" and "doxastic" paradoxes into a delightful tapestry. Some have seen connections between the surprise exam and the sorites paradox ("removing one grain of sand from a heap of sand leaves it a heap so zero grains of sand is still a heap"); see [8], [26], and [31]. A connection with the paradox of Schrödinger's cat is discussed in [14] and [19].

\section{Acknowledgments}

The USENET newsgroup rec . puzzles has played an important role in my understanding of the surprise examination paradox. I am indebted to an unknown contributor to the rec.puzzles archive who compiled a list of about thirty references; reading these papers some five years ago constituted my first serious attempt to understand the paradox. I am grateful for the encouragement of Chris Cole, the maintainer of the rec.puzzles archive, and of Bill Taylor, whose enlightening and witty correspondence has had a lot of influence on this paper. Roy Sorensen, Dale Jacquette, and Martin Gardner have helped with my literature search. Thanks finally to Jim Propp for suggesting that I submit this paper to the MonTHLY, and to all my friends who have patiently endured my ramblings on the paradox over the years.

\section{References}

1. C. A. Anderson, The paradox of the knower, J. Phil. 80 (1983), 338-355.

2. N. Asher and H. Kamp, The knower's paradox and representational theories of attitudes, in Theoretical Aspects of Reasoning About Knowledge: Proceedings of the 1986 Conference, March 19-22, 1986, Monterey, California, ed. J. Y. Halpern, Morgan Kaufmann, Los Altos, California (1986), pp. 131-147.

3. R. Binkley, The surprise examination in modal logic, J. Phil. 65 (1968), 127-136.

4. J. Bosch, The examination paradox and formal prediction, Logique et Analyse 15 (1972), 505-525.

5. J. Cargile, The surprise test paradox, J. Phil. 64 (1967), 550-563.

6. J. M. Chapman and R. J. Butler, On Quine's 'so-called paradox,' Mind 74 (1965), 424-425.

7. D. Clark, How expected is the unexpected hanging? Math. Mag. 67 (1994), 55-58.

8. P. Dietl, The surprise examination, Educational Theory 23 (1973), 153-158.

9. M. Edman, The prediction paradox, Theoria 40 (1974), 166-175. 
10. H. B. Enderton, A Mathematical Introduction to Logic, Academic Press, New York (1972).

11. F. Fitch, A Goedelized formulation of the prediction paradox, Amer. Phil. Quart. 1 (1964), 161-164.

12. D. Fudenberg and J. Tirole, Game Theory, MIT Press, Cambridge, MA (1991).

13. P. Grim, Operators in the paradox of the knower, Synthese 94 (1993), 409-428.

14. J. M. Holtzman, A note on Schrödinger's cat and the unexpected hanging paradox, British J. Phil. Sci. 39 (1988), 397-401.

15. D. Kaplan and R. Montague, A paradox regained, Notre Dame J. Formal Logic 1 (1960), 79-90.

16. R. L. Kirkham, On paradoxes and a surprise exam, Philosophia 21 (1991), 31-51.

17. R. C. Koons, Doxastic paradox and reputation effects in iterated games, Theoretical Aspects of Reasoning About Knowledge: Proceedings of the Fourth Conference (TARK 1992), March 22-25, 1992, Monterey, California, ed. Y. Moses, Morgan Kaufmann, San Mateo, California (1992), pp. 60-72.

18. I. Kvart, The paradox of surprise examination, Logique et Analyse 21 (1978), 337-344.

19. J. G. Loeser, Three perspectives on Schrödinger's cat, Amer. J. Physics 52 (1984), 1089-1093; letters and replies, 53 (1985), 937 and 54 (1986), 296-297.

20. A. Margalit and M. Bar-Hillel, Expecting the unexpected, Philosophia 13 (1983), 263-288.

21. T. H. O'Beirne, Can the unexpected never happen? New Scientist 10 (1961), 464-465; letters and replies, 597-598.

22. D. Olin, The prediction paradox resolved, Phil. Studies 44 (1983), 225-233.

23. D. Olin, Predictions, intentions, and the prisoner's dilemma, Phil. Quart. 38 (1988), 111-116.

24. W. V. O. Quine, On a so-called paradox, Mind 62 (1953), 65-67.

25. R. Shaw, The paradox of the unexpected examination, Mind 67 (1958), 382-384.

26. J. W. Smith, The surprise examination on the paradox of the heap, Phil. Papers 13 (1984), 43-56.

27. R. Smullyan, Forever Undecided: A Puzzle Guide to Gödel, Knopf, New York (1987), parts I-V, particularly chapter 2.

28. R. A. Sorensen, Recalcitrant versions of the prediction paradox, Australasian J. Phil. 69 (1982), 355-362.

29. R. A. Sorensen, Conditional blindspots and the knowledge squeeze: a solution to the prediction paradox, Australasian J. Phil. 62 (1984), 126-135.

30. R. A. Sorensen, Blindspots, Clarendon Press, Oxford (1988).

31. T. Williamson, Inexact knowledge, Mind 101 (1992), 217-242.

32. P. Windt, The liar in the prediction paradox, Amer. Phil. Quart. 10 (1973), 65-68.

Tellabs Research Center

One Kendall Square

Cambridge, MA 02139

tchowATalumDOTmitDOTedu 


\title{
The Surprise Examination or Unexpected Hanging Paradox: An Exhaustive Bibliography
}

\author{
Timothy Y. Chow \\ tchowATalumDOTmitDOTedu
}

When writing [Cho], I tried very hard to compile an exhaustive bibliography for the surprise exam paradox. I believe I came very close to succeeding, but the MoNTHLY refused to publish it, saying that extensive bibliographies are not appropriate for MONTHLY articles. I am therefore making the bibliography freely available on the web instead. I will try to update this bibliography continually; if you know of any references that are not listed here, please let me know!

The list below was last updated June 25, 2011. (The last previous ArXiv update was made on September 6, 2005.) Minor updates have been made to some entries: [Clk], [Cra], [Frn], [Jac], [K-M], [Kea], [Loe], [Sob]. As one might expect, Google Scholar proved to be an invaluable tool for discovering new references, including some such as [Lan], [Ge1], [Pri], [Kaw], and [Chn] that I had previously overlooked despite publication dates of 1986, 1999, 2000, 2002, and 2002 respectively. At the same time, Google Scholar generated many hits that I was not sure I wanted to include. Some people had written substantial articles or given talks on the paradox but had not (yet) formally published them; in the end, I decided to exclude unpublished items from this bibliography (though I did allow for dissertations such as [Mar] and electronic publications such as [So13]). Other papers were primarily concerned with some other topic and made only passing reference to the paradox, or used the paradox just as an illustrative example of something. These papers I evaluated on a case-by-case basis and made a personal judgment call; I decided to include [Ald], [Cuo], [Da1], [Da2], [Fas], [Gin], [Gra], [H-H], [K11], [K12], [L-K], and [WHR], but omitted a number of others. Specifically, I decided that the Kaplan-Montague paradox of the knower was distinct from the surprise examination paradox, and I even went back and deleted some entries that I had included in previous versions of my bibliography that were concerned only with the paradox of the knower.

Following my previous practice, I included books that contained a substantial discussion of the paradox even if most of the book was devoted to other topics; in this category were [Cv2], [Cv3], [Kim], [So12], and [T-H]. And of course, I documented a steady stream of new publications on the paradox: [Cv1], [DK1], [DK2], [F-B], [Ge2], [G-C], [Hu], [Hua], [Kna], [K-R], [Lvy], [ØGS], [Prr], [Sav], [S-W], [Váz], [Wm1], [Wm2], and [Zha]. Of these, [Prr] (see also the accompanying commentary in [ØGS]) is one of the most interesting because it is a previously unpublished manuscript that probably dates from the early 1950's.

Finally, in addition to the acknowledgments that I made in previous versions of this bibliography, I would like to thank Sandy Lemberg and Arthur Benjamin for notifying 
me about some of the new references above, and Hans van Ditmarsch, Paul Franceschi, Lasse Burri Gram-Hansen, Ran Raz, and John Williams for keeping me informed about their own research on the paradox.

\section{References}

[Ald] D. Aldous, Stopping times and tightness II, The Annals of Probability 17 (1989), 586-595.

[Ale] P. Alexander, Pragmatic paradoxes, Mind 59 (1950), 536-538.

[Aud] R. Audi (ed.), The Cambridge Dictionary of Philosophy, Cambridge University Press, New York (1995), entries on paradox and unexpected examination paradox.

[Au1] A. K. Austin, On the unexpected examination, Mind 78 (1969), 137.

[Au2] A. K. Austin, The unexpected examination, Analysis 39 (1979), 63-64.

[Aye] A. J. Ayer, On a supposed antinomy, Mind 82 (1973), 125-126.

[B-C] J. Bennett and J. Cargile, Reviews, Journal of Symbolic Logic 30 (1965), 101-103.

[Ber] J. L. Bermúdez, Rationality and the backwards induction argument, Analysis 59 (1999), 243-248.

[Bin] R. Binkley, The surprise examination in modal logic, Journal of Philosophy 65 (1968), 127-136.

[Blk] S. Blackburn, The Oxford Dictionary of Philosophy, Oxford University Press, Oxford (1994), entry on prediction paradox.

[Bla] U. Blau, Vom Henker, vom Lügner und vom ihrem Ende, Erkenntnis 19 (1983), 27-44.

[BB1] J. Blau and U. Blau, Epistemische Paradoxien I, Dialectica 49 (1995), 169-193.

[BB2] J. Blau and U. Blau, Epistemische Paradoxien II, Dialectica 50 (1996), 167-182.

[BBM] D. Borwein, J. M. Borwein and P. Maréchal, Surprise maximization, American Mathematical Monthly 107 (2000), 517-527.

[Bos] J. Bosch, The examination paradox and formal prediction, Logique et Analyse 15 (1972), 505-525.

[Bov] L. Bovens, The backward induction argument for the finite iterated prisoner's dilemma and the surprise exam paradox, Analysis 57 (1997), 179-186.

[Bun] B. Bunch, Mathematical Fallacies and Paradoxes, Van Nostrand, New York (1982), 34-37.

[Car] J. Cargile, The surprise test paradox, Journal of Philosophy 64 (1967), 550-563.

[Cas] J. Case, Paradoxes involving conflicts of interest, American Mathematical Monthly 107 (2000), 33-43.

[Cv1] P. Cave, Reeling and A-reasoning: Surprise examinations and Newcomb's tale, Philosophy 79 (2004), 609-616.

[Cv2] P. Cave, Can a Robot Be Human? 33 Perplexing Philosophy Puzzles, Oneworld (2009), Chapter 11.

[Cv3] P. Cave, This Sentence is False: An Introduction to Philosophical Paradoxes, Continuum (2009), Chapter 2.

[Cha] T. S. Champlin, Quine's judge, Philosophical Studies 29 (1976), 349-352.

[C-B] J. M. Chapman and R. J. Butler, On Quine's 'so-called paradox,' Mind 74 (1965), 424-425.

[Chi] C. Chihara, Olin, Quine and the surprise examination, Philosophical Studies 47 (1985), 191-199.

[Cho] T. Y. Chow, The surprise examination or unexpected hanging paradox, American Mathematical Monthly 105 (1998), 41-51.

[Cla] D. Clark, How expected is the unexpected hanging? Mathematics Magazine 67 (1994), 55-58.

[Clk] M. Clark, Paradoxes from A to Z, Routledge, London, 2002, entries on The Unexpected Examination and The Designated Student.

[Cl1] R. Clark, Pragmatic paradox and rationality, Canadian Journal of Philosophy 24 (1994), 229-242.

[C12] R. Clark, Reflection and truth, in Theoretical Aspects of Reasoning About Knowledge: Proceedings of the Fourth Conference (TARK 1992), March 22-25, 1992, Monterey, California, ed. Y. Moses, Morgan Kaufmann, San Mateo, California (1992), 73-84. 
[Chn] D. H. Cohen, Informal logic \& the surprise exam, Informal Logic 22 (2002), TS 22-27.

[Coh] L. J. Cohen, Mr. O'Connor's "pragmatic paradoxes," Mind 59 (1950), 85-87.

[Cra] E. Craig (ed.), Routledge Encyclopedia of Philosophy, Routledge, New York (1998), entry on paradoxes, epistemic; also in Concise Routledge Encyclopedia of Philosophy, Routledge, New York (2000), and The Shorter Routledge Encyclopedia of Philosophy, New York (2005).

[Cuo] M. A. Cuonzo, How to solve paradoxes: A taxonomy and analysis of solution-types, Cogency 1 (2009), 9-21.

[D-S] J. Dancy and E. Sosa (eds.), A Companion to Epistemology, Basil Blackwell Ltd., Cambridge, MA (1992), entry on surprise examination paradox.

[Da1] E. Davis, A first-order theory of communicating first-order formulas, Proceedings of the Ninth International Conference on Principles of Knowledge Representation and Reasoning, June 2-5, 2004, Whistler, Canada, ed. D. Dubois, C. A. Welty, and M.-A. Williams, AAAI Press (2004), 235-245.

[Da2] E. Davis, Knowledge and communication: A first-order theory, Artificial Intelligence 166 (2005), 81-139.

[Die] P. Dietl, The surprise examination, Educational Theory 23 (1973), 153-158.

[DK1] H. van Ditmarsch and B. Kooi, The secret of my success, Synthese 151 (2006), 201-232; erratum (republication): 153 (2006), 339.

[DK2] H. van Ditmarsch and B. Kooi, Een analyse van de Hangman Paradox in dynamische epistemische logica, Algemeen Nederlands Tijdschrift voor Wijsbegeerte 97 (2005), 16-30.

[Edm] M. Edman, The prediction paradox, Theoria 40 (1974), 166-175.

[Edw] P. Edwards (ed.), The Encyclopedia of Philosophy, Crowell Collier and MacMillan, Inc., New York (1967), entry on logical paradoxes.

[E-F] G. W. Erickson and J. A. Fossa (eds.), Dictionary of Paradox, University Press of America, Inc., Lanham, MD (1998), entries on Hollis's paradox and prediction paradox, the.

[Fal] N. Falletta, The Paradoxicon, Doubleday and Co., Inc., Garden City, NY (1983), 161-166.

[Fas] M. Fasli, Towards a first-order approach for social agents: Preliminary report, Proceedings of the Twelfth International Florida Artificial Intelligence Research Society (FLAIRS) Conference, ed. A. Kumar and I. Russell, 1999.

[Fer] K. G. Ferguson, Equivocation in the surprise exam paradox, Southern Journal of Philosophy 29 (1991), 291-302.

[F-B] J. L. Ferreira and J. Z. Bonilla, The surprise exam paradox, rationality, and pragmatics: A simple game-theoretic analysis, Journal of Economic Methodology 15 (2008), 285-299.

[Fit] F. Fitch, A Goedelized formulation of the prediction paradox, American Philosophical Quarterly 1 (1964), 161-164.

[Frn] P. Franceschi, Une analyse dichotomique pour le paradoxe de l'examen-surprise, Philosophiques 32 (2005),399-421. [Formerly titled: A straightforward reduction of the surprise examination paradox to the sorites paradox.]

[Fra] J. T. Fraser, Note relating to a paradox of the temporal order, in The Voices of Time, ed. J. T. Fraser, University of Massachusetts Press, Amherst (1981), 524-526.

[Ful] J. S. Fulda, The paradox of the surprise test, The Mathematical Gazette 75 (1991), 419-421.

[Gal] P. Galle, Another note on the "surprise test" puzzle, Informal Logic Newsletter 3 (1981), 21-22.

[GaS] G. Gamow and M. Stern, The date of the hanging, in Puzzle-Math, Viking Press, New York (1958), 23-27.

[Ga1] M. Gardner, A new prediction paradox, British Journal for the Philosophy of Science 13 (1962), 51.

[Ga2] M. Gardner, A new paradox, and variations on it, about a man condemned to be hanged, Scientific American 208 (March 1963), 144-154; reprinted in: The Unexpected Hanging and Other Mathematical 
Diversions: With a New Afterword and Expanded Bibliography, University of Chicago Press, Chicago (1991), chapter 1 and afterword; The Colossal Book of Mathematics: Classic Puzzles, Paradoxes, and Problems, W. W. Norton \& Company, New York (2001), chapter 43; Martin Gardner's Mathematical Games [CD-ROM], Mathematical Association of America, 2005.

[Ga3] M. Gardner, Further Mathematical Diversions, Penguin Books (1977), chapter I.

[Ga4] M. Gardner, The erasing of Philbert the fudger, in Science Fiction Puzzle Tales, Clarkson Potter, New York (1981), puzzle 20.

[Ga5] M. Gardner, aha! Gotcha: Paradoxes to Puzzle and Delight, W. H. Freeman and Company, San Francisco (1982), 26-27.

[Ga6] M. Gardner, Again, how's that again? in Riddles of the Sphinx and Other Mathematical Puzzle Tales, Mathematical Association of America, Washington, D.C. (1987), chapter 27.

[Gea] J. Geanakoplos, The hangman's paradox and Newcomb's paradox as psychological games, Cowles Foundation Discussion Paper \#1128, Cowles Foundation, Yale University, 1996.

[Ge1] J. Gerbrandy, Bisimulations on Planet Kripke, Ph.D. thesis, University of Amsterdam, 1999.

[Ge2] J. Gerbrandy, The surprise examination in dynamic epistemic logic, Synthese 155 (2007), 21-33.

[GiS] I. Gilboa and D. Schmeidler, Information dependent games: Can common sense be common knowledge? Economics Letters 27 (1988), 215-221.

[Gin] H. Gintis, Rationality and its discontents (review of Rational Decisions by Ken Binmore), The Economic Journal 120 (2010), F162-F180.

[Go1] L. Goldstein, Inescapable surprises and acquirable intentions, Analysis 53 (1993), 93-99.

[Go2] L. Goldstein, Examining boxing and toxin, Analysis 63 (2003), 242-244.

[G-C] L. Goldstein and P. Cave, A unified Pyrrhonian resolution of the toxin problem, the surprise examination, and Newcomb's puzzle, American Philosophical Quarterly 45 (2008), 365-376.

[Gra] R. Grafstein, Taking Dworkin to Hart: A positivist conception of institutional rules, Political Theory 11 (1983), 244-265.

[Gui] S. Guiasu, Prediction paradox revisited, Logique et Analyse 30 (1987), 147-154.

[Hal] N. Hall, How to set a surprise exam, Mind 108 (1999), 647-703.

[H-M] J. Y. Halpern and Y. Moses, Taken by surprise: the paradox of the surprise test revisited, Journal of Philosophical Logic 15 (1986), 281-304.

[Hrd] R. Hardin, Collective Action, Johns Hopkins University Press, Baltimore (1982), 145-150.

[Har] C. Harrison, The unanticipated examination in view of Kripke's semantics for modal logic, in Philosophical Logic, ed. J. W. Davis, D. J. Hockney and K. Wilson, D. Reidel, Dordrecht (1969), 74-88.

[H-H] J. Heather and D. Hill, I'm not signing that! Proceedings of the First International Workshop on Formal Aspects in Security and Trust (FAST 2003), September 8-9, 2003, Pisa, ed. T. Dimitrakos and F. Martinelli (2003), 71-82.

[Hel] N. S. K. Hellerstein, Delta, A Paradox Logic, World Scientific, Singapore (1997), 230-232.

[Hil] M. Hild, Auto-epistemology and updating, Philosophical Studies 92 (1998), 321-361.

[Ho1] M. Hollis, A paradoxical train of thought, Analysis 44 (1984), 205-206.

[Ho2] M. Hollis, More paradoxical epistemics, Analysis 46 (1986), 217-218.

[Hon] T. Honderich (ed.), The Oxford Companion to Philosophy, 2nd ed., Oxford University Press, New York (2005), entries on examination paradox and prediction paradox.

[Hz1] J. M. Holtzman, An undecidable aspect of the unexpected hanging problem, Philosophia 17 (1987), 195-198.

[Hz2] J. M. Holtzman, A note on Schrödinger's cat and the unexpected hanging paradox, British Journal for the Philosophy of Science 39 (1988), 397-401. 
[Hu] Y.-L. Hu, Dui "Turan yanxi beilun" de fenxi (Analysis of the "surprise drill paradox"), Journal of Chongqing Institute of Technology (2007), no. 12, 81-85.

[Hua] B. Huang, Egg, tiger, and hangman-Analyses on epistemic paradoxes, Journal of Southwest University (Social Science Edition) (2010), no. 5.

[HSW] C. Hudson, A. Solomon, R. Walker, A further examination of the 'surprise examination paradox,' Eureka 32 (1969), 23-24.

[H-B] P. Hughes and G. Brecht, Vicious Circles and Infinity: A Panoply of Paradoxes, Doubleday, Garden City, NY (1975), 41-61.

[Jac] F. Jackson, The easy examination paradox, in Analytical Philosophy in Comparative Perspective: Exploratory Essays in Current Theories and Classical Indian Theories of Meaning and Reference, Springer (1984), 151-159; reprinted with minor revisions in F. Jackson, Conditionals, Basil Blackwell, Oxford (1987), chapter 7.

[Ja1] D. Jacquette, Review of Roy Sorensen's Blindspots, Journal of Speculative Philosophy 3 (1989), 218-223.

[Ja2] D. Jacquette, A deflationary resolution of the surprise event paradox, Iyyun: The Jerusalem Philosophical Quarterly 41 (1992), 335-349.

[Ja3] D. Jacquette, On the designated student and related induction paradoxes, Canadian Journal of Philosophy 24 (1994), 583-592.

[Jan] C. Janaway, Knowing about surprises: a supposed antinomy revisited, Mind 98 (1989), 391-409.

[JK1] B. Jongeling and T. Koetsier, A reappraisal of the hangman paradox, Philosophia 22 (1993), 299-311.

[JK2] B. Jongeling and T. Koetsier, Blindspots, self-reference, and the prediction paradox, Philosophia 29 (2002), 377-391.

[Kal] M. G. Kalin, A tighter noose for the hangman, International Logic Review 22 (1980), 105-106.

[Kan] S. Kanger, The paradox of the unexpected hangman, in Wright and Wrong: Mini Essays in Honor of Georg Henrik von Wright on His Sixtieth Birthday, June 14, 1976, ed. K. Segerberg, Group in Logic and Methodology of Real Finland (1976), 19-23.

[K-M] D. Kaplan and R. Montague, A paradox regained, Notre Dame Journal of Formal Logic 1 (1960), 79-90. Reprinted in Formal Philosophy: Selected Papers of Richard Montague, ed. R. H. Thomason, Yale University Press (1974), 271-285.

[Kaw] Y. Kawano, Gödel's incompleteness and forcing, Algorithms in Algebraic Systems and Computation Theory, RIMS Kokyuroku 1268 (2002), 126-137.

[Kea] J. Kearns, An illocutionary logical explanation of the surprise execution, History and Philosophy of Logic 20 (1999), 195-213.

[K-E] J. Kiefer and J. Ellison, The prediction paradox again, Mind 74 (1965), 426-427.

[Kim] S. O. Kimbrough, Agents, Games, and Evolution: Strategies at Work and Play, Taylor \& Francis (in press), Chapter 19.

[Kin] M. Kinghan, A paradox derailed: reply to Hollis, Analysis 46 (1986), 20-24.

[Ki1] R. L. Kirkham, The two paradoxes of the unexpected examination, Philosophical Studies 49 (1986), 19-26.

[Ki2] R. L. Kirkham, On paradoxes and a surprise exam, Philosophia 21 (1991), 31-51.

[K11] R. Klein, Under "pragmatic" paradoxes, Yale French Studies 66, The Anxiety of Anticipation (1984), 91-109.

[K12] R. Klein, The future of nuclear criticism, Yale French Studies 77, Reading the Archive: On Texts and Institutions (1990), 76-100; reprinted in Yale French Studies 97, 50 Years of Yale French Studies: A Commemorative Anthology, Part 2: 1980-1998 (2000), 78-102.

[Kna] M. J. Knauff, The surprise examination paradox: A rejection of Quine, and alternate solutions, The Yale Philosophy Review 4 (2008), 8-16. 
[Kra] M. H. Kramer, Another look at the problem of the unexpected examination, Dialogue 38 (1999), 491-501.

[K-R] S. Kritchman and R. Raz, The surprise examination paradox and the second incompleteness theorem, Notices of the American Mathematical Society 57 (2010), 1454-1458; letter in response by S. Alexander, 58 (2011), 527.

[Kva] I. Kvart, The paradox of surprise examination, Logique et Analyse 21 (1978), 337-344.

[Lan] F. Landman, Paradoxes of elimination, in Towards a Theory of Information: The Status of Partial Objects in Semantics, GRASS 6, Foris (1986), 183-228.

[Lee] B. D. Lee, The paradox of the surprise examination revisited, in Circularity, Definition and Truth, ed. A. Chapuis, Indian Council of Philosophical Research (2000), 247-254.

[Lei] J. Leiber, Paradoxes, Gerald Duckworth \& Co., Ltd., London (1993), 79-80.

[Len] W. Lenzen, Die Paradoxie der überraschenden Übung: logische, epistemologische und pragmatische Aspekte, Logique et Analyse 19 (1976), 267-284.

[Lev] D. S. Levi, Surprise! Southern Journal of Philosophy 38 (2000), 447-464.

[Lvy] K. Levy, The solution to the surprise exam paradox, The Southern Journal of Philosophy 47 (2009), 131-158.

[L-K] J. Li and G. Kendall, Finite iterated prisoner's dilemma revisited: Belief change and end-game effect, Proceedings of the Behavioral and Quantitative Game Theory (BQGT '10): Conference on Future Directions, Mary 14-16, 2010, Newport Beach, CA, USA (2010), Article 48.

[Lin] B. Linsky, Factives, blindspots and some paradoxes, Analysis 46 (1986), 10-15.

[Loe] J. G. Loeser, Three perspectives on Schrödinger's cat, American Journal of Physics 52 (1984), 1089-1093; letters and replies, P. J. Bussey, 53 (1985), 937 and C. Kacser, 54 (1986), 296-297.

[Lyo] A. Lyon, The prediction paradox, Mind 68 (1959), 510-517.

[Mac] J. J. Macintosh, Aquinas and Ockham on time, predestination and the unexpected examination, Franciscan Studies 55 (1998), 181-220.

[Mar] A. Marcoci, The surprise examination paradox in dynamic epistemic logic, M.Sc. thesis, University of Amsterdam, 2010.

[M-B] A. Margalit and M. Bar-Hillel, Expecting the unexpected, Philosophia 13 (1983), 263-288.

$[\mathrm{McC}] \mathrm{J}$. McClelland, Epistemic logic and the paradox of the surprise examination, International Logic Review 3 (1971), 69-85.

[M-C] J. McClelland and C. Chihara, The surprise examination paradox, Journal of Philosophical Logic 4 (1975), 71-89.

[Med] B. Medlin, The unexpected examination, American Philosophical Quarterly 1 (1964), 66-72; corrigenda, 333.

[Mel] B. Meltzer, The third possibility, Mind 73 (1964), 430-433.

[M-G] B. Meltzer and I. J. Good, Two forms of the prediction paradox, British Journal for the Philosophy of Science 16 (1965), 50-51.

[Met] U. Metschl, Eine kleine Überraschung für Gehirne im Tank: Eine skeptische Notiz zu einem antiskeptischen Argument, Zeitschrift für philosophische Forschung 43 (1989), 519-527.

[M-H] J.-J. Ch. Meyer and W. van der Hoek, A modal constrastive logic: The logic of 'but,' Annals of Mathematics and Artificial Intelligence 17 (1996), 291-313.

[Nai] M. A. Nait Abdallah, Logic programming of some mathematical paradoxes, in Fundamentals of Computation Theory: Proceedings, International Conference FCT '89, Szeged, Hungary, August 21-25, 1989, ed. J. Csirik, J. Demetrovics, and F. Gécseg, Lecture Notes in Computer Science, vol. 380, SpringerVerlag, New York (1989), 349-361.

[Ner] G. Nerlich, Unexpected examinations and unprovable statements, Mind 70 (1961), 503-513.

[Nie] H. A. Nielsen, A note on the "surprise test" puzzle, Informal Logic Newsletter 2 (1979), 6-7. 
[OB1] T. H. O'Beirne, Can the unexpected never happen? New Scientist 10 (1961), 464-465; letters and replies, 597-598.

[OB2] T. H. O'Beirne, Puzzles and Paradoxes: Fascinating Excursions in Recreational Mathematics, Dover Press, New York (1984), chapter 11.

[OCa] M. J. O'Carroll, Improper self-reference in classical logic and the prediction paradox, Logique et Analyse 10 (1967), 167-172.

[OCo] D. J. O'Connor, Pragmatic paradoxes, Mind 57 (1948), 358-359.

[ØGS] P. Øhrstrøm, L. .B. Gram-Hansen, and U. Sandborg-Petersen, Time and knowledge: Some reflections on Prior's analysis of the paradox of the prisoner, Synthese, to appear. DOI: 10.1007/s11229-011-0048-y

[O11] D. Olin, The prediction paradox resolved, Philosophical Studies 44 (1983), 225-233.

[O12] D. Olin, The prediction paradox: resolving recalcitrant variations, Australasian Journal of Philosophy 64 (1986), 181-189.

[Ol3] D. Olin, On a paradoxical train of thought, Analysis 46 (1986), 18-20.

[O14] D. Olin, On an epistemic paradox, Analysis 47 (1987), 216-217.

[Ol5] D. Olin, Predictions, intentions, and the prisoner's dilemma, Philosophical Quarterly 38 (1988), 111-116.

[Ol6] D. Olin, Paradox, McGill-Queen's University Press, Montreal \& Kingston (2003), chapter 3.

[Par] G. Pareti, I paradossi pragmatici: bibliografia, Rivista di Filosofia 69 (1978), 170-174.

[Pit] V. Pittioni, Das Vorhersageparadoxon, Conceptus 17 (1983), 88-92.

[Pop] K. R. Popper, A comment on the new prediction paradox, British Journal for the Philosophy of Science $\mathbf{1 3}$ (1962), 51.

[Pos] C. J. Posy, Epistemology, ontology, and the continuum, in The Growth of Mathematical Knowledge, ed. E. Grosholz, Synthese Library, vol. 289, Kluwer, Dordrecht (2000), 199-219.

[Pou] W. Poundstone, Labyrinths of Reason: Paradox, Puzzles, and the Frailty of Knowledge, Anchor Press/Doubleday, New York (1988), chapter 6.

[Pri] G. Priest, The logic of backwards inductions, Economics and Philosophy 16 (2000), 267-285.

[Prr] A. N. Prior, The paradox of the prisoner in logical form, Synthese, to appear. DOI: 10.1007/s11229-0119947-z

[Qui] W. V. O. Quine, On a so-called paradox, Mind 62 (1953), 65-67; reprinted in The Ways of Paradox, and Other Essays, Harvard University Press, Cambridge, MA (1976), chapter 2.

[Reg] D. H. Regan, Utilitarianism and Cooperation, Clarendon Press, Oxford (1980), page 74.

[Res] N. Rescher, Paradoxes: Their Roots, Range, and Resolution, Carus Publishing Co., Chicago and La Salle (2001), 112-114.

[Sai] R. M. Sainsbury, Paradoxes, 2nd edition, Cambridge University Press, Cambridge (1995), sections 4.2-4.4.

[Sav] M. vos Savant, Ask Marilyn, PARADE, December 5, 2004.

[Sck] F. Schick, Surprise, self-knowledge, and commonality, The Journal of Philosophy 97 (2000), 440-453.

[Sch] J. Schoenberg, A note on the logical fallacy in the paradox of the unexpected examination, Mind 75 (1966), 125-127.

[S-W] B. Schumacher and M. Westmoreland, Reverend Bayes takes the unexpected examination, Math Horizons (September 2008), 26-27.

[Scr] M. Scriven, Paradoxical announcements, Mind 60 (1951), 403-407.

[Sha] S. C. Shapiro, A procedural solution to the unexpected hanging and sorites paradoxes, Mind 107 (1998), 751-761.

[Shp] R. A. Sharpe, The unexpected examination, Mind 74 (1965), 255. 
[Shw] R. Shaw, The paradox of the unexpected examination, Mind 67 (1958), 382-384.

[Sla] B. H. Slater, The examiner examined, Analysis 35 (1974), 49-50.

[Smi] J. W. Smith, The surprise examination on the paradox of the heap, Philosophical Papers 13 (1984), 43-56.

[Smu] R. Smullyan, Forever Undecided: A Puzzle Guide to Gödel, Knopf, New York (1987), parts I-V, particularly chapter 2.

[Sob] E. Sober, To give a surprise exam, use game theory, Synthese 115 (1998), 355-373; addendum available on the author's website at http://philosophy.wisc.edu/sober/surp-add.pdf

[So1] R. A. Sorensen, Recalcitrant versions of the prediction paradox, Australasian Journal of Philosophy 69 (1982), 355-362.

[So2] R. A. Sorensen, Conditional blindspots and the knowledge squeeze: a solution to the prediction paradox, Australasian Journal of Philosophy 62 (1984), 126-135.

[So3] R. A. Sorensen, The bottle imp and the prediction paradox, Philosophia 15 (1986), 421-424.

[So4] R. A. Sorensen, A strengthened prediction paradox, Philosophical Quarterly 36 (1986), 504-513.

[So5] R. A. Sorensen, Blindspotting and choice variations of the prediction paradox, American Philosophical Quarterly 23 (1986), 337-352.

[So6] R. A. Sorensen, The bottle imp and the prediction paradox, II, Philosophia 17 (1987), 351-354.

[So7] R. A. Sorensen, Blindspots, Clarendon Press, Oxford (1988).

[So8] R. A. Sorensen, The vagueness of knowledge, Canadian Journal of Philosophy 17 (1987), 767-804.

[So9] R. A. Sorensen, The earliest unexpected class inspection, Analysis 53 (1993), 252.

[So10] R. A. Sorensen, Infinite "backward" induction arguments, Pacific Philosophical Quarterly 80 (1999), 278-283.

[So11] R. A. Sorensen, Formal problems about knowledge, in The Oxford Handbook of Epistemology, ed. P. K. Moser, Oxford University Press, New York (2002), 539-568.

[So12] R. A. Sorensen, Paradoxes of rationality, in The Oxford Handbook of Rationality, ed. A. R. Mele and P. Rawling, Oxford University Press (2004), 267-268.

[So13] R. A. Sorensen, Epistemic paradoxes, in The Stanford Encyclopedia of Philosophy (online), Spring 2009 edition, http://plato.stanford.edu

[Sta] M. Stack, The surprise examination paradox, Dialogue 16 (1977), 207-212.

[Ste] I. Stewart, Paradox lost, Manifold 10 (1971), 19-20; D. Woodall replies, 21.

[Tha] M. Thalos, Conflict and co-ordination in the aftermath of oracular statements, The Philosophical Quarterly 47 (1997), 212-226.

[T-H] T. Tymoczko and J. Henle, Sweet Reason: A Field Guide to Modern Logic, Springer (1999), 420-428.

[Váz] M. Vázquez, Knowledge, information and surprise, tripleC 7 (2009), 194-201.

[V-E] V. Vieru and V. Enache, The surprise-test paradox: A formal study, Studies in Informatics and Control 8 (1999), 317-327.

[Wtb] R. Weintraub, Practical solutions to the surprise examination paradox, Ratio (New Series) 8 (1995), 161-169.

[Wei] P. Weiss, The prediction paradox, Mind 61 (1952), 265-269.

[WHR] H. Wietze de Haan, W. H. Hesselink, and G. R. Renardel de Lavalette, Knowledge-based asynchronous programming, Fundamenta Informaticae 63 (2004), 259-281.

[Wm1] J. Williams, A simple solution to the surprise exam paradoxes, Research Collection School of Social Sciences (2004), Paper 26.

[Wm2] J. N. Williams, The surprise exam paradox: Disentangling two reductios, Journal of Philosophical Research 32 (2007), 67-94. 
[Wi1] T. Williamson, Review of Roy Sorensen's Blindspots, Mind 99 (1990), 137-140.

[Wi2] T. Williamson, Inexact knowledge, Mind 101 (1992), 217-242.

[Wi3] T. Williamson, Knowledge and Its Limits, Oxford University Press, New York (2000), chapter 6.

[Win] P. Windt, The liar in the prediction paradox, American Philosophical Quarterly 10 (1973), 65-68.

[Woo] D. R. Woodall, The paradox of the surprise examination, Eureka 30 (1967), 31-32.

[Wr1] M. J. Wreen, Surprising the examiner, Logique et Analyse 26 (1983), 177-190.

[Wr2] M. J. Wreen, Passing the bottle, Philosophia 15 (1986), 427-444.

[W-S] C. Wright and A. Sudbury, The paradox of the unexpected examination, Australasian Journal of Philosophy 55 (1977), 41-58.

[Wri] J. A. Wright, The surprise exam: prediction on last day uncertain, Mind 76 (1967), 115-117.

[Wu] K. J. Wu, Believing and disbelieving, in The Logical Enterprise, ed. A. R. Anderson et al., Yale University Press, New Haven (1975), 211-219.

[Zha] T.-S. Zhang, On hangman paradox, Academic Journal of Jinyang (2006), no. 1. 